\title{
Influence of Negative Transfer of Dialects on English Pronunciation and Teaching Strategies
}

\author{
Lihong Wang ${ }^{a,}{ }^{*}$, Weijie Gou ${ }^{\text {b }}$ \\ Beijing Polytechnic, Beijing 100176, China \\ a, *wlhjane@12.com, b gvjie@126.com
}

\begin{abstract}
In the process of students' learning English pronunciation, some pronunciation errors caused by the negative transfer of Chinese are caused. If these negative transfer effects of Chinese cannot be overcome, it will hinder the improvement of students' listening and speaking skills. This article analyzes the impact of negative dialect transfer on English phonetics learning from three aspects: phoneme, coherent pronunciation and intonation, and proposes some coping strategies, hoping to instruct teachers to help students overcome the impact of negative dialect transfer and improve their English pronunciation level during the listening and speaking teaching process.
\end{abstract}

Keywords: English Learning; Negative Transfer of Dialects; Second Language; Teaching Strategy.

\section{Introduction}

Many domestic scholars have made comparisons between Mandarin, dialects and English pronunciation, and some discussions have been made to talk about the influence of dialects on foreign language learning. However, no systematic studies and comparisons have been made on the influence of dialects on foreign language listening and speaking ability. The accurate mastery of English pronunciation plays an important role in improving the comprehensive English ability of second language learners, because the accuracy of the pronunciation will directly affect the accuracy of listening, the learning of vocabulary and the progress of oral communication $[1,2]$.

It is found in English teaching process that students will be affected by the negative dialect transfer during the learning process, which is also a significant reason hindering students from improving their English pronunciation. The pronunciation habits of students' dialect or Chinese can easily affect their English pronunciation, making English pronunciation becomes very unnatural. If students can overcome the influence of negative transfer from dialects in the process of learning pronunciation, their English pronunciation will be closer to the pronunciation of English native speakers. This article will analyze the specific impact of negative transfer of Chinese on students' English phonetic learning and explore strategies to overcome these impacts and improve their English phonetic ability.

\section{Transfer Theory}

Transfer is a term derived from psychology category, which refers to the process in which learners transfer the previously mastered knowledge and experience and apply them to learning and mastering new knowledge when they acquire new knowledge. Language transfer, originally derived from behaviorist psychology, was proposed by Robert Lado in "Cross-Cultural Linguistics" in 1957. He believed: "In the process of second foreign language acquisition, language learners try to transfer the characteristics of their dialects to a second language. If the structures of the two languages are similar, positive transfer will occur, and if the structures of the two languages are different, negative transfer or interference will occur [3]."

Odlin summarized the definition of language transfer in 1987 as: the impact of the commonalities and differences between the target language and any other language that has been acquired (or not fully acquired). He further summarized the performance of negative transfer into four categories: "Less utilization", "overuse", "using error" and "misunderstanding" [4].

In RodEllis's book he believes "Second Language Acquisition" that the negative transfer of dialects is one of the root causes of errors in the learning process of second language learners [5]. The 
performance of negative transfer of dialects is particularly obvious in Chinese students' English learning. Ellis' research shows that $51 \%$ of the mistakes made by learners who take Chinese as a dialect in their English learning process come from dialect interference [6]. This is because Chinese belongs to the Sino-Tibetan language family, while English belongs to the Latin language family. There are differences in the structure. Therefore, if Chinese students can overcome the influence of negative transfer when learning English, the effect of learning English will be greatly improved.

\section{The Influence of Negative Transfer of Dialects on English Phonetics Learning}

\subsection{Research Foundation}

The influence of negative transfer is particularly prominent in phonetic acquisition of second language. Allan James pointed out: "The influence of the structure of native language on the structure of second language is much greater in phonetics than in other aspects. Because learning a new phonetic system means learning new pronunciation and auditory patterns. These patterns belong to physical aspects of language behavior, they are more resistant to changes and adjustments than the cognitive aspects of language behavior." [7] In order to help students, overcome the influence of negative transfer of dialects in English phonetics learning, we analyzed the specific problems and reasons the students in our school encountered in phonetics learning, to explore ways to improve the effect of English phonetics teaching.

135 students were researched, they are from Henan, Hubei, Hunan, Sichuan, Chongqing, Zhejiang, Guangxi, Shandong, Shaanxi, Gansu, Shanxi and other regions. In the process of teaching English phonetics, we found that there are some common things when students from different provinces, cities, and regions are affected by negative dialect transfer. Through the follow-up study of students in different regions, the influence of negative dialect transfer on English phoneme learning, English coherent sentence learning, and English intonation learning will be discussed in turns.

\subsection{The Influence of Negative Transfer of Dialects on Phoneme Learning}

\subsubsection{The Influence of Negative Transfer of Dialects on English Consonant Learning}

(1) The phenomenon of adding vowels after consonants. In Chinese teaching, for the convenience of teaching, some initial consonants use their calling sounds, that is, sounds made with a vowel after the initial consonants, such as bo, po, mo, fo, de, te, ne, le, which sounds like English [b], [p], [m], [f], [d] [t], [n], [1]. However, the vocal cords of these initial consonants are vibrated during the pronunciation, while some consonants in English are not vibrated during the pronunciation, that is, unvoiced consonants. Due to the influence of negative dialect transfer, some students are accustomed to adding a vowel after some words ending in a consonant, such as: map [mæp] is pronounced [mæp $]$, book [bok] is pronounced [brkə], big [big] is pronounced [bigə].

(2) $[\mathrm{v}]$ and $[\mathrm{w}]$ are confused. There is only [f] in Chinese, while there are [f] and [v] in English. Therefore, some students find it a little difficult when they read [v] and will use [w] instead. For example: verywell ['veri wel] is pronounced as ['weri wel].

(3) $[\theta]$ is pronounced as $[\mathrm{s}]$ or $[ð]$ is pronounced as $[\mathrm{z}]$. The dental sounds $[\theta]$ and [ð] in English are a difficult problem for many Chinese students when learning English pronunciation, because the tip of the tongue should be lightly against the upper teeth when this set of sounds is pronounced, and the airflow comes from the gap formed between the tip of the tongue and the edge of upper teeth, thus produces a fricative sound, which does not exist in Chinese, which leads students to use [s] and [z]

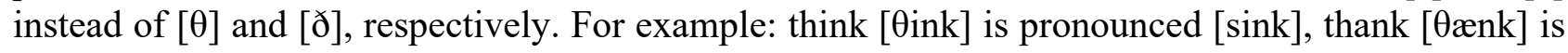
pronounced [sænk], they[ðei] is pronounced [zei], and that [ðæt] is pronounced [zæt].

(4) $\left[\int\right]$ is pronounced as [s]. in some southern areas, such as Hunan, there is no distinction between blade-alveolar and retroflex in the local dialect. Most of the tongue sounds $\mathrm{zh}, \mathrm{ch}$, sh are pronounced 
as z, c, s. Therefore, it is easy for students from these places to pronounce [C] in English as [s]. For example: shop [ $\left.\int \mathrm{pp}\right]$ is pronounced as [spp], shake [ $\left.\mathrm{feik}\right]$ is pronounced as [seik].

(5) $\left[\int\right]$ is pronounced as "xi", and [t $\left.\int\right]$ is pronounced as "qii". There are no fricatives such as $\left[\int\right]$ and $[\mathrm{t}]$ in Henan and Hubei dialects, so students usually use xi and qi instead. For example: information [,infə'meifən] is pronounced as [,infə'meixiən], and teach [ti:tf] becomes [ti:qi].

(6) Swallow /m/sound. In some areas, such as Hubei, Zhejiang, Guangxi, etc., the local dialect lacks back nasal sounds. For example, "jing" is pronounced as "jin", and students in these places will omit some of the ending sounds [m]. For example, name [neim] is pronounced as [nei], and time [taim] is is pronounced as [tai].

(7) [n] and [1] are confused. Students from Gansu, Hubei, Hunan, and Sichuan have no distinction between $\mathrm{n}$ and 1 in their dialects. For example, "milk" (niunai) is pronounced as liulai. [n] and [1] in English are indistinguishable for them. For example: knife [naif] is pronounced as life [laif], and know [nəv] is pronounced as low [ləo].

(8) Dark [1] is pronounced [əv]. The side sound [1] in English has two pronunciations, one is the clear sound before the vowel, and the other is the dark sound before the consonant or at the end. The clear [1] sounds similar to le in Chinese, such as: leave [li:v], late [leit]. The dark [1] has no similar pronunciation in Chinese, so students use [əテ] instead. For example: fill[fil]is pronounced as[fiəv], belt[belt] becomes [beəut] [8].

\subsubsection{The Influence of Negative Transfer of Dialects on English Vowel Learning}

Compared with the influence of negative dialect transfer on English consonant learning, English vowels are less affected by negative dialect transfer, but the following problems still exist.

(1) Confusion of long vowels and short vowels. The monophthongs in English can be divided into long vowels and short vowels according to the length of their pronunciation, while there is no difference in the length of pronunciation of monophthongs in Chinese. Therefore, when students pronounce long vowels, it often sounds the same as the pronunciation of short vowels, although they can realize that the sound should be pronounced longer. For example: sheep [ $\mathrm{fi}: \mathrm{p}]$ is pronounced as ship[fip], and fool[fu:1] is pronounced as [fol].

(2) Monophthongs are pronounced as diphthongs. There is a compound vowel "ai" in Chinese, but there is no vowel [e] or [æ]. This makes students accustomed to use "ai" instead of a single sound. When students pronounced [e] or [æ], there is a sliding on the mouth shape, which sounds like the diphthong [ai]in English. Such as: cat [kæt] is pronounced as kite [kait].

\subsection{The Influence of Negative Dialect Transfer on the Learning of English Coherent Pronunciation}

\subsubsection{The Influence of Negative Transfer of Dialects on Consonant Connection}

Chinese pronunciation sounds articulately. The reason is as mentioned above. Some initial consonants in Chinese use their calling sounds during the teaching process. The pronunciation is very clear. In addition, every Chinese character is a syllable, and the pronunciation must be very clear and loud. Therefore, the pronunciation of Chinese is not like the case where the unvoiced consonants do not vibrate the vocal cords in English. Because of this difference, the students tried to pronounce each consonant clearly when they pronounced consonants in English, thus they could not reach the standard pronunciation. For example: [k] in actor['æktə] is silent, and [d] in goodbye[,god'bai] is silent [9]. But some students will pronounce them as ['ækətə] and [,godə'bai].

\subsubsection{The Influence of Negative Transfer of Dialects on Stress}

Each word in English can contain two or more syllables, and there are light and heavy syllables in the word. However, a Chinese character only contains one syllable, and there is no distinction between light and heavy syllables. So, some students feel confused about the position of the stress of a multisyllable English word, not knowing which syllable the stress should fall on. For example, during the teaching process, the author found some examples of mispronunciation of stress position: Students will pronounce 'interesting as in'teresting. In addition, there are some words that have two stresses, 
one main stress and one secondary stress. Students usually read only one stress. For example, they pronounce, revo'lution as 'revolution, refu'gee as 'refugee and so on.

\subsubsection{The Influence of Negative Transfer of Dialects on Rhythm}

The rhythm of English refers to the alternating occurrence of stressed syllables and unstressed syllables at roughly equal intervals. [10] Therefore, English is timed by stress, that is, a stressed syllable occupies the length of a unit of time. If the number of words in the two sentences is not equal, but the number of stressed syllables is the same, then the two sentences will take the same length of time when they are read. Chinese is a language that is timed by syllables, that is, each syllable, or each Chinese character, occupies the length of a unit of time when it is pronounced. Because of this difference students are used to pronouncing every word clearly and very long when reading English sentences. like:

I 'think he 'wants to 'go.

I 'think that he "wants us to 'go.

I 'think it was an 'excellent af' fair.

In the above three sentences, although the number of words and syllables in each sentence is different, the number of the stressed syllables in each sentence is the same, so the time to read these three sentences is also the same. However, due to the influence of negative dialect transfer, students will pronounce every syllable very clearly, resulting in a longer duration of the second and third sentences.

\subsubsection{The Influence of Negative Transfer of Dialect on English Intonation Learning}

There are three common intonations in English: rising, falling, and falling rising. And the intonation change in English appears on the last stressed syllable of the entire intonation group, while every Chinese character in Chinese has an intonation. For this reason, some students add tones to each word, and each word has a tone like in Chinese. For example:

They have a charming little house on the shore.

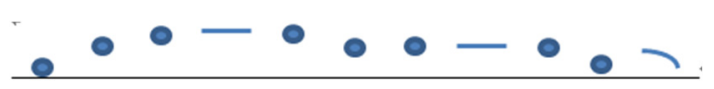

Fig 1. Example 1

Due to the negative transfer of dialects, the sentence will sound like:

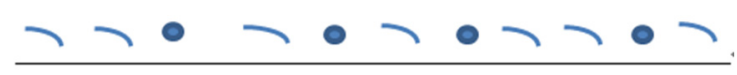

Fig 2. Example 2

Note: _ $\_$stands for stressed syllable, $\longrightarrow$ stands for falling tone, ostands for unstressed syllable

\section{Coping Strategies for English Phonetics Teaching}

It can be seen from the above that when college students learn English pronunciation, they are mainly affected by the negative transfer of dialects. If the habit of Chinese pronunciation is used instead of English pronunciation, errors will occur. Therefore, in the process of English phonetics teaching, effective measures should be taken to overcome the influence of negative transfer of dialects.

\subsection{Comparing Chinese and English When Practicing}

In the teaching process, teachers should analyze the differences between Chinese and English pronunciation at the right time, compare the similarities and differences between the two, and use the positive transfer of dialects to overcome the negative transfer of dialects. For example, when explaining English phonemes, you can compare and analyze the differences between phonemes in English and initial consonants and vowels in Chinese. For example, the pronunciation of the front 
vowel [i:] in English is like the pronunciation of "yi" in Chinese, but there is a difference between the tongue position and the pronunciation length. When we pronounce /i:/, the tip of tongue touches the inferior gingiva, the tongue position is lower than "yi", and [i:] is a long vowel, so it is pronounced longer than "yi".

\subsection{Imitating and Correcting Pronunciation Simultaneously}

Imitation is one of the most effective ways to learn phonetics. Teachers can help students choose correct materials, equipped with audio of clear and standard pronunciation, so that students can listen and imitate to read. During the teaching process, the author tried to provide students with some short essays to imitate and recite, and achieved good results. In addition, in the phonetic class, teachers should give students sufficient opportunities to practice pronunciation, such as reading words and sentences aloud, dialogue exercises, reading poetry and essays, etc. In the process of reading aloud, teachers can find students' mistakes and correct them in time.

\subsection{Reading Poems can Cultivate a Sense of Rhythm}

The requirement of English pronunciation for rhythm is very important in reading English aloud, especially when reading English poetry. In English poetry, the number of stressed syllables in each line of poetry is usually the same, and the length of time for reading each line is roughly the same. Therefore, recite poems and nursery rhymes can clearly feel the rhythm of English pronunciation. During the teaching process, the author provided students with poems, nursery rhymes or tongue twisters to practice certain phonemes, and led the students to read aloud and sing together, which not only enlivened the atmosphere in classroom, but also cultivated the students' sense of rhythm in English pronunciation. In addition, the author also led the students to appreciate English poems to help them feel the rhythm of English.

\subsection{Strengthen the Practice of Chinese}

From the previous analysis, it is not difficult to see that one of the reasons for some phonetic errors is that students can't speak standard Chinese. For example, some southern students cannot distinguish between $/ \mathrm{n} /$ and $/ 1 /$ in Chinese, which makes them unable to pronounce [n] and [1] in English clearly. In the dialects of some places there are no blade alveolar or retroflex, which makes it impossible for students in these places to pronounce [J] and [s] correctly. Therefore, teachers should encourage students to strengthen the practice of Chinese, make good use of the positive transfer of Chinese pronunciation in English pronunciation learning, and overcome the negative transfer of some dialects in English pronunciation learning, which will not only improve the standard of Chinese, but also improve their English pronouncing level.

\section{Summary}

In the process of English listening and speaking teaching, teachers should help students correctly analyze the similarities and differences between English and Chinese pronunciation, effectively make use of positive transfer of dialects, and strive to overcome the impact of negative transfer of dialects on phonetic learning. However, these analyses can't just be on paper. Students should strengthen imitation exercises and teachers should correct wrong pronunciation in time, use flexible teaching methods to stimulate students' interest in learning, and improve students' English pronunciation.

\section{Acknowledgments}

This work was financially supported by Beijing Polytechnic Research fund. 


\section{References}

[1] Lado R. Linguistics Across Culture [M. Michigan: University of Michigan Press, 1957: 27-29.

[2] Odlin, T. Language Transfer [M]. Cambridge: Cambridge University Press, 1989: 101-110.

[3] Luo Hongmei. A Study on the Negative Transfer of Dialects to Students' English Phonetics Learning[J]. Campus English, 2020(47):34-35.

[4] Huang Lingqing, Zhu Siming. A Study of Oral English Teaching Strategies in Duyun Region under the Influence of Dialects[J]. English Square,2020(12):51-53.

[5] Song Yan, Wang Hongxi, Wang Shuaiqi. On the Influence of Dialects on English Pronunciation from the Theory of Transfer--Taking Shandong fang Dialect as an example[J]. English Square,2020(01):66-67.

[6] Ma Li. The influence of the negative transfer of Chinese northern dialects on English pronunciation and teaching strategies[J]. Foreign Language Education Research,2019,7(02):11-18.

[7] Zhang Huanxin, Dong Qian. The influence of dialects on the English pronunciation of local students in Dalian[J]. Nongjia Staff,2019(04):214-215+238.

[8] Fang Peng, Shen Ling. An Empirical Study on the Negative Transfer of Dialects to English Intonation by Praat Image [J]. Journal of Civil Aviation Flight College of China, 2018,29(05):77-80.

[9] Duan Qiaoling. Analysis of the influence of Chinese dialects on English phonetics acquisition[J]. Contemporary Tourism (Golf Travel),2018(01):193.

[10] Deng Sha, Tan Yazi, Ou Yaosheng. The influence of local accent on non-English majors' English pronunciation and its correction[J]. Xueyuan,2017(25):147+157.

[11] Yang Ming. The influence of negative transfer of dialects on English phonetics acquisition and counter measures [J]. Journal of Suzhou Education Institute,2017,20(02):133-134. 